\title{
Ensaio de cisalhamento de interface com vistas a camadas de pavimentos
}

\author{
Interface shear test for pavement layers
}

\section{Renan Gustavo Scherer ${ }^{1}$, Deividi da Silva Pereira², Eduardo Londero Druzian ${ }^{3}$, Cléber Faccin ${ }^{4}$, Luciano Pivoto Specht ${ }^{5}$}

1Universidade Federal de Santa Maria, Rio Grande do Sul - Brasil, renangscherer@gmail.com

2Universidade Federal de Santa Maria, Rio Grande do Sul - Brasil, dsp@ufsm.br

3Universidade Federal de Santa Maria, Rio Grande do Sul - Brasil, eduardo-druzian@hotmail.com

${ }^{4}$ Universidade Federal de Santa Maria, Rio Grande do Sul - Brasil, crfaccin@gmail.com

5Universidade Federal de Santa Maria, Rio Grande do Sul - Brasil, luspecht@ufsm.br

\section{Recebido:}

20 de outubro de 2018

Aceito para publicação:

25 de janeiro de 2019

Publicado:

15 de dezembro de 2020

Editor de área:

Jorge Barbosa Soares

\section{Palavras-chaves:}

Cisalhamento de interfaces.

Ensaio de laboratório.

Pavimentação.

\section{Keywords:}

Interface shear.

Laboratory test.

Paving.

DOI:10.14295/transportes.v28i4.1878

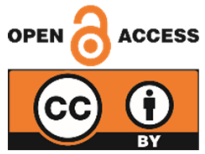

\begin{abstract}
RESUMO
A aderência entre camadas aglutinadas e granulares de pavimentos tem se mostrado um importante fator na modelagem do seu desempenho. Contudo, a investigação acerca de qual é a real condição das interfaces tem apresentado dificuldades quanto à avaliação experimental. Este trabalho tem por objetivo apresentar um ensaio de cisaIhamento de interfaces aplicável a duas camadas de materiais, podendo uma delas ser ou não aglutinada. Para tanto, foram desenvolvidos moldes que garantem a integridade da camada granular e um aparato, acoplável em prensas universais, que permite a realização do ensaio de cisalhamento com aplicação de tensão normal controlada. Com isto, foi possível a obtenção da tensão de cisalhamento e do deslocamento relativo entre as camadas durante todo o ensaio. Conforme avaliações realizadas, o ensaio desenvolvido se mostrou eficiente na determinação das tensões de cisalhamento na interface, indicando que a resistência ao cisalhamento mensurada é representativa da real resistência da interface.
\end{abstract}

\begin{abstract}
The bonded between agglutinated and granular layers of pavements has been shown to be an influential factor in their estimated performance. However, research on the real condition of interfaces has presented difficulties in experimental evaluation. This work aims to present an interface shear test applicable to two layers of materials, one of which may or may not be bonded. For this, molds that guarantee the integrity of the granular layer and an apparatus that allows the shear test with application of controlled normal stress, attachable in a universal testing machines, have been developed. With this, it was possible to obtain the shear stress and the relative displacement between the layers throughout the test. According to the evaluation, the test was efficient in determining the shear stresses at the interface, indicating that the shear strength measured is representative of the real interface strength.
\end{abstract}

\section{INTRODUÇÃO}

A questão da aderência entre camadas aglutinadas e não aglutinadas de pavimentos tem sido foco de interesse, em especial em períodos recentes. Todavia, as pesquisas em geral se restringem em demonstrar a influência deste fenômeno no cômputo dos esforços no pavimento. A verificação da real condição de interface ainda apresenta dificuldades operacionais para sua determinação em ensaios laboratoriais ou de campo. 
A influência da aderência entre camadas no desempenho de pavimentos é demonstrada numericamente em trabalhos como os de Torquato e Silva et al. (2015), Scherer et al. (2016), Santos et al. (2017) e Torquato e Silva et al. (2020). Estes estudos indicam que quando a interface revestimento asfáltico/base granular é simulada em condição não aderida, os esforços, deformações e deslocamentos estimados são superiores àqueles avaliados em condições análogas, porém com esta mesma interface considerada aderida. Contudo, o emprego de interface aderida ou não aderida não consiste de uma decisão de projeto, mas sim uma definição que deve representar de maneira adequada o real comportamento dos pavimentos em campo. Assim, a investigação experimental reveste de especial interesse e importância.

Laboratorialmente, a melhor e mais empregada forma de avaliação desta condição, conforme Canestrari et al. (2013) e Raposeiras et al. (2013), é através do cisalhamento da interface. Ainda segundo os mencionados autores, esta avaliação pode ser realizada por meio da resistência ao cisalhamento $(\tau)$ ou do módulo de reação ao cisalhamento $(K)$, expresso na Equação (1). Contudo, a maioria dos ensaios disponíveis não são adequados quando uma das camadas não é aglutinada, como as usualmente empregadas no Brasil em bases de pavimentos, tal qual a brita graduada simples (BGS). A avaliação da resistência ao cisalhamento da interface desta camada granular com uma camada de revestimento em material aglutinado, como o concreto asfáltico (CA), necessita de equipamentos que permitam o ensaio mantendo a integridade da camada não aglutinada desde a moldagem até o final do ensaio.

\begin{tabular}{lll} 
& & \multicolumn{1}{c}{$K=\frac{\tau}{\Delta x}$} \\
onde: & $\mathrm{K}:$ & Módulo de reação ao cisalhamento (MPa/mm); \\
& $\tau:$ & Resistência ao cisalhamento (MPa); \\
& $\Delta \mathrm{x}:$ & Deslocamento relativo da interface na ruptura (mm).
\end{tabular}

Assim, o presente trabalho tem por objetivo apresentar um ensaio de cisalhamento de interface, concebido para ser empregado com duas camadas de materiais, podendo estes serem ou não aglutinados. Buscou-se a simplificação do ensaio, mas que este permitisse a realização do cisalhamento com aplicação de distintas tensões normais sobre a amostra. Também se buscou que fosse possível a mensuração da tensão de cisalhamento e do deslocamento relativo das camadas durante todo o ensaio, para que, além da resistência ao cisalhamento, outras avaliações pudessem ser realizadas, como a do módulo de reação ao cisalhamento.

No âmbito internacional, diversos ensaios e equipamentos para a avaliação da resistência ao cisalhamento em interfaces já foram propostos. A Figura 1 mostra alguns destes ensaios. Em (1-A), tem-se o ensaio de cisalhamento de Leutner; em (1-B), o LPDS; em (1-C), o ensaio de cisalhamento FDOT; em (1-D), o ensaio de cisalhamento LCB; em (1-E), o ASTRA; e em (1-F), o ensaio de Torquato e Silva (2017).

O ensaio de cisalhamento de Leutner (Figura 1-A) é um dos mais comuns para avaliação da resistência ao cisalhamento entre camadas por seu arranjo ser relativamente simples e o ensaio ser rápido. Consiste em gerar um deslocamento na interface através da aplicação de uma força, com a obtenção da resistência ao cisalhamento na interface. 0 ensaio é realizado em prensas Marshall, CBR ou UTM (Universal Testing Machine), com uso de um dispositivo para apoiar o corpo-de-prova (CP) e gerar o cisalhamento. Empregam-se amostras com diâmetros de $100 \mathrm{~mm}$ ou $150 \mathrm{~mm}$, taxa de deslocamento de $50,8 \mathrm{~mm} / \mathrm{min}$ e temperatura de ensaio de $20{ }^{\circ} \mathrm{C}$. (LEUTNER, 1979; SUTANTO, 2009; CANASTRERI et al., 2013; GUIMARÃES, 2013). Conforme Canestrari et al. (2013), não há uma folga entre os anéis de corte na interface, o que pode fazer com 
que a resistência ao cisalhamento sofra influência dos agregados das camadas, além disso, não é possível aplicar uma força normal à interface analisada. 0 ensaio também não garante a manutenção da integridade da camada granular, pois é realizado com as camadas não confinadas, não sendo indicado, portanto, para este caso.
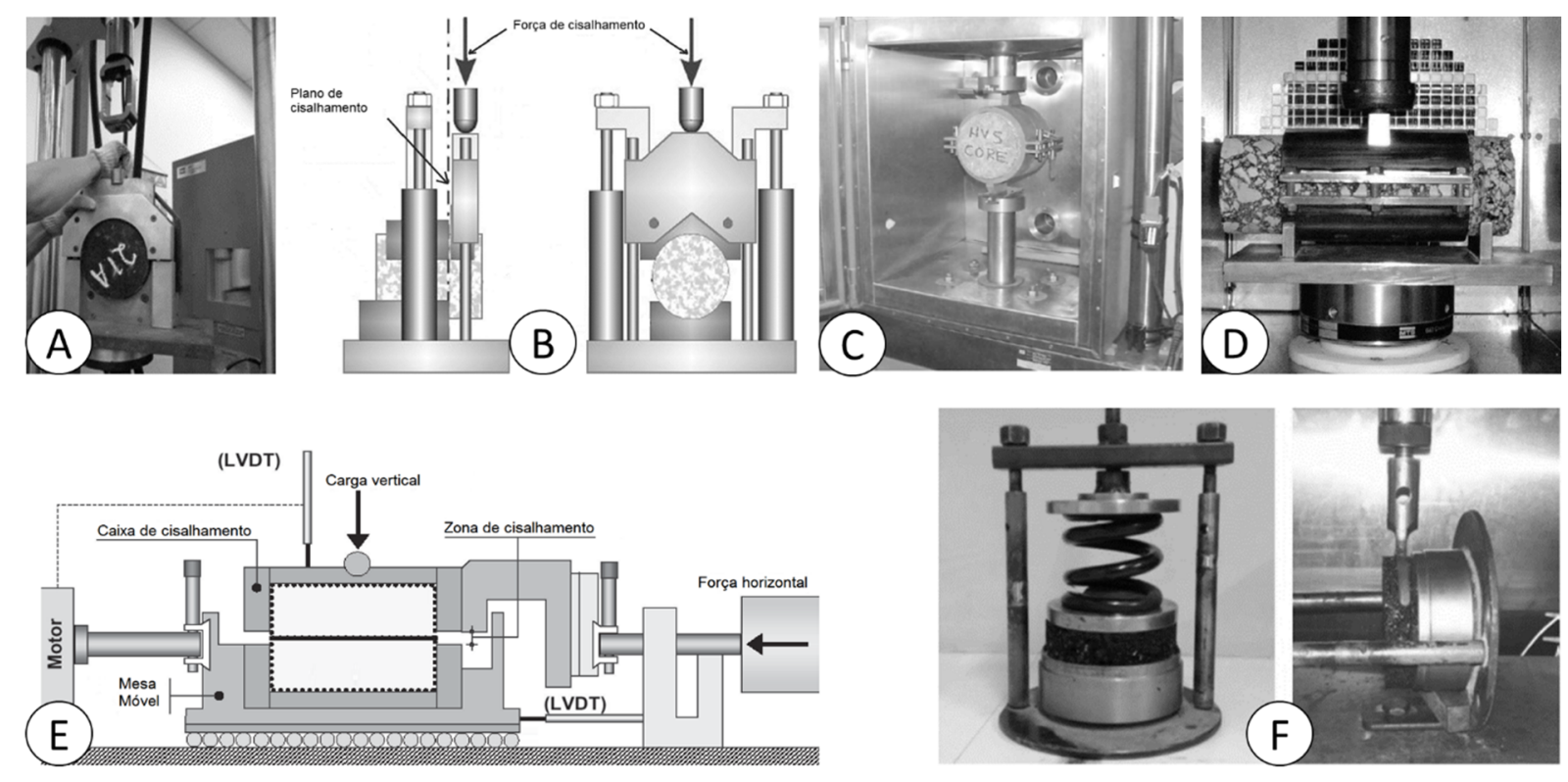

Figura 1. Exemplos de Ensaios de Cisalhamento da Interface de Camadas. Fonte/Adaptado de: (A) Guimarães (2013), (B) Raab e Partl (2009), (C) Tashman (2006), (D) Miró et al. (2006), (E) Canestrari et al. (2005) e (F) Torquato e Silva (2017)

O LPDS (Layer Parallel Direct Shear) (Figura 1-B) é uma versão modificada do ensaio de Leutner, desenvolvida na Suíça. Conforme Raab e Partl (2009), suas principais diferenças são o acréscimo de um espaçamento de $5 \mathrm{~mm}$ na interface, núcleo do corpo-de-prova sob pressão e possibilidade de ajuste para diâmetros de $148 \mathrm{~mm}$ à $155 \mathrm{~mm}$ ou amostras prismáticas de 150 $\mathrm{mm}$ por $130 \mathrm{~mm}$. Para o ensaio, uma parte do corpo-de-prova fica suspensa e a outra é apoiada em um suporte "U", no qual é aplicado uma força que gera um deslocamento constante de 50,8 $\mathrm{mm} / \mathrm{min}$, através de uma prensa Marshall. Apesar das modificações, o equipamento também não garante a integridade da camada não coesiva e não permite a aplicação de uma tensão normal sobre a amostra.

O ensaio de cisalhamento FDOT (Florida Department of Transportation) (Figura 1-C) é um ensaio similar aos anteriores. É realizado com temperatura controlada em amostras de duas camadas, com o equipamento permitindo um espaçamento livre de 4,8 $\mathrm{mm}$ na interface. Para a execução do ensaio, é realizada a aplicação de um deslocamento em uma das partes do corpo-de-prova à uma velocidade de $50,8 \mathrm{~mm} / \mathrm{min}$ e medida a força máxima na ruptura (TASHMAN et al., 2006). São empregados corpos-de-prova com diâmetro de 152,4 mm (6 in), ensaiados à $25^{\circ} \mathrm{C}$. As camadas permanecem confinadas, o que ajuda a manter a integridade do material granular, contudo, não é possível a aplicação de tensão normal.

O Ensaio de Cisalhamento LCB (Laboratorio de Caminos de Barcelona) (Figura 1-D) é um ensaio de cisalhamento com uma configuração diferente daqueles anteriores, baseado em três pontos. Miró et al. (2006) explicam que para o ensaio é empregado um corpo-de-prova 
cilíndrico, com diâmetro de 101,6 mm, disposto como viga sobre dois apoios afastados $200 \mathrm{~mm}$ entre si. Para que ocorra o cisalhamento uma força é aplicada na vertical de modo a gerar um deslocamento constante de $1,27 \mathrm{~mm} / \mathrm{min}$, cerca de $5 \mathrm{~mm}$ da seção de corte, para ser desprezível o efeito do momento fletor gerado. Conforme Sutanto (2009), o afastamento entre os apoios exige um corpo-de-prova grande, havendo a atuação, ainda que pequena, de um momento fletor na interface. Também não é possível registrar o deslocamento relativo na interface nem aplicar uma tensão normal sobre a amostra. Além disto, as camadas não ficam confinadas, não podendo ser empregado para materiais granulares.

O ASTRA (Ancona Cisalhament Testing Research and Analysis) (Figura 1-E) é um aparelho de cisalhamento direto similar aos utilizados na mecânica dos solos. Permite a aplicação da força de cisalhamento em conjunto com uma carga normal proveniente de um sistema de pesos. São empregados corpos-de-prova cilíndricos ou prismáticos. A caixa de cisalhamento é composta de duas partes, separadas por uma região não-confinada. 0 ensaio é realizado com um deslocamento de 2,5 mm/min. Dois LVDTs medem os deslocamentos vertical e horizontal (CANESTRARI et al., 2005). 0 ensaio realiza a medição da força de cisalhamento e dos deslocamentos em função do tempo e, com isso, é possível calcular as tensões de cisalhamento e normal em cada instante, sobre a área efetiva. Com estes valores, é possível ainda calcular o módulo de reação ao cisalhamento (K). Desde 2007 está normatizado na Itália através da norma UNI/TS 11214. O sistema de pesos para aplicação da força normal dificulta seu uso com valores mais elevados de tensão normal, como aqueles relacionados às pressões de inflação de pneus de veículos, de interesse para a pavimentação e para a pesquisa de aderência a ser realizada.

Torquato e Silva (2017) apresentou um dos únicos ensaios de cisalhamento de interface voltados especificamente para uma camada granular e uma camada asfáltica de pavimentos (Figura 1-F). 0 equipamento desenvolvido pelo autor consiste de um molde com uma haste roscada e uma mola para a aplicação da tensão normal, acoplável à uma prensa UTM, onde é realizado o cisalhamento. 0 molde é composto de dois cilindros, sendo o inferior rosqueado em um fundo e o superior simplesmente sobreposto ao inferior. A haste parafusada transmite o esforço normal à camada superior por meio de uma mola, cuja constante elástica foi determinada, permitindo o cálculo da força aplicada através da Lei de Hooke. 0 carregamento transversal, responsável pelo cisalhamento, é aplicado por uma prensa UTM, a uma taxa de $20 \mathrm{kPa} / \mathrm{s}$ (TORQUATO E SILVA, 2017). Torquato e Silva (2017) empregou este equipamento em ensaios com tensões normais de até $100 \mathrm{kPa}$ e em Torquato e Silva et al. (2018), resultados obtidos com este ensaio são empregados na proposta de um modelo constitutivo da interface. Para tensões normais mais elevadas, contudo, a utilização do equipamento é dificultada, dadas as dimensões da mola que seria necessária para a transmissão de tensões normais superiores.

Além destes, há ainda outros métodos para a avaliação da resistência ao cisalhamento na interface. Contudo, tendo em vista as necessidades de uma futura pesquisa de resistência ao cisalhamento entre camadas a ser realizada para avaliar a aderência entre a camada de base (em BGS) e de revestimento (em CA) de pavimentos, nenhum é plenamente adequado. Para este estudo, é necessário um equipamento que permita o ensaio de amostras em que uma das camadas é de material granular (como a BGS), garantindo sua integridade. Também, que possibilite a atuação concomitante da tensão cisalhante e da tensão normal, em magnitudes mais elevadas, como àquelas impostas por veículos aos pavimentos. Além disto, que seja possível o acompanhamento contínuo da tensão de cisalhamento e do deslocamento relativo na interface durante o ensaio. Devido a isto, foi desenvolvido o método de ensaio apresentado neste artigo. 


\section{CARACTERIZAÇÃO BÁSICA DOS MATERIAIS E PREMISSAS PARA O DESENVOLVIMENTO DO ENSAIO}

Conforme mencionado, existem diversos ensaios que buscam avaliar a resistência ao cisalhamento na interface de camadas. Contudo, boa parte deles são voltados aos casos em que ambos os materiais constituintes são aglutinados. A partir desta constatação, foi desenvolvido um ensaio de resistência ao cisalhamento na interface, visando a avaliação da aderência entre camadas, aplicável ao caso de camada granular com camada aglutinada. Para tal, foram elencadas as caraterísticas esperadas e comparadas às descrições dos diversos ensaios e equipamentos similares disponíveis. Com isto, e considerando os avanços e as dificuldades apresentadas por Torquato e Silva (2017) no desenvolvimento do seu equipamento, foi concebido e executado o ensaio apresentado neste trabalho.

Para a concepção do ensaio, teve-se como premissas que este fosse de simples montagem e realização, sem necessidade de grandes equipamentos e que, ao mesmo tempo, garantisse a conservação da integridade da camada granular até o fim do ensaio. Além disto, que permitisse a medição do deslocamento relativo entre as camadas. Conforme será apresentado no item de resultados, estes critérios levaram ao desenvolvimento de moldes para duas camadas de materiais, com a interface livre para a ruptura por cisalhamento, conjuntamente com um aparato para realizar o ensaio em uma prensa servo-hidráulica UTM 25 da IPC Global.

A fim de verificar a aplicabilidade da metodologia desenvolvido e seus resultados, foram realizados alguns ensaios com o uso desta. Avaliou-se a resistência ao cisalhamento e o módulo de reação ao cisalhamento para amostras compostas de base granular e revestimento asfáltico, com interface imprimada. Os ensaios foram realizados à $25^{\circ} \mathrm{C}$ e foram estipulados dois valores de tensão normal, 0,55 MPa e 0,83 MPa (aproximadamente 80 psi e 120 psi, respectivamente), relacionados à pressão de inflação dos pneus, para aplicação sobre as amostras.

Os materiais de base, revestimento e imprimação foram provenientes da duplicação da ERS-509, em Santa Maria, RS, ambos coletados em campo. A BGS possui teor de umidade ótima de 7,5\%, correspondente a uma massa específica seca máxima de $2.260 \mathrm{~kg} / \mathrm{m}^{3}$ do ensaio Proctor Modificado. 0 revestimento, em asfalto borracha, possui massa específica de 2.246 $\mathrm{kg} / \mathrm{m}^{3}$ e foi compactado com a mesma energia utilizada na moldagem Marshall. A imprimação foi realizada com asfalto diluído CM-30, aplicado sobre a base após esta estar curada e varrida com pincel. Os procedimentos de ensaios serão explicados juntos com a apresentação do equipamento desenvolvido.

\section{RESULTADOS}

0 desenvolvimento do ensaio de resistência ao cisalhamento na interface foi realizado de maneira a seguir os critérios mencionados no item de metodologia. 0 equipamento, apresentado em 3.1, em sua concepção final é composto de moldes e de um aparato de ensaio. As moldagens são efetuadas por impacto e a ruptura em prensa servo-hidráulica. Foram realizados ensaios que permitiram comprovar a funcionalidade da metodologia, apresentados em 3.2 e também verificações de possíveis influências do equipamento nos valores mensurados com seu uso, demonstradas em 3.3. 


\subsection{Equipamento e Metodologia de Ensaio Desenvolvidos 3.1.1. Moldes e Procedimento de Moldagem das Amostras}

Conforme já mencionado, o molde necessário deveria comportar duas camadas de material e garantir a integridade da camada granular, permitindo o cisalhamento na interface. Outro aspecto importante era que seu formato fosse compatível com os métodos de compactação disponíveis e que a superfície de cada camada já ficasse plana e uniforme com a compactação, dispensando correções, como a de rasar a camada, que poderiam acarretar em fragilidade na superfície. Assim, foi desenvolvido um molde composto de três anéis e um fundo. Além disto, para a moldagem de revestimento, é empregado um prolongador, idêntico ao utilizado com os moldes Marshall. A Figura 2 apresenta um dos moldes confeccionados, desmontado em (A) e montado em (B). Todos os elementos são em aço.
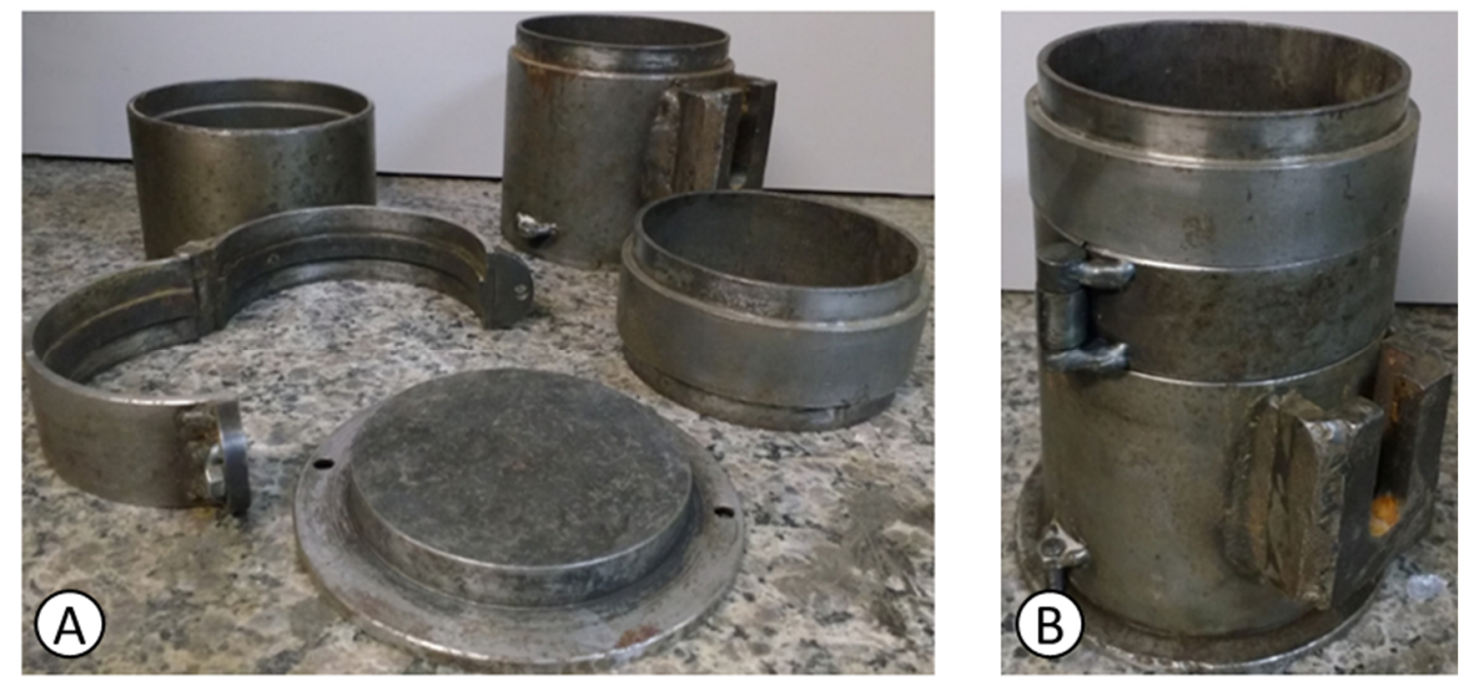

Figura 2. Exemplo de molde confeccionado

0 anel inferior acomoda a maior parte da base em BGS, o superior, a maior parte do material de revestimento, em CA, já o intermediário, que internamente possui apenas $10 \mathrm{~mm}$ de altura, recebe base e revestimento, cada um ocupando metade de sua altura ( $5 \mathrm{~mm} / \mathrm{cada}$ ). 0 anel inferior possui ainda um suporte, que serve para prendê-lo ao atuador da prensa onde o ensaio é realizado, recebendo através dele o deslocamento que provoca o cisalhamento. 0 fundo é aparafusado ao anel inferior. Após a moldagem, a base deve ter $100 \mathrm{~mm}$ de altura de material, para a interface ficar no centro da altura livre para o cisalhamento. Já o revestimento pode ter até $60 \mathrm{~mm}$ de altura.

0 ensaio é realizado com as camadas confinadas pelos anéis superior e inferior e pelo fundo do molde. 0 anel intermediário é o que permite o cisalhamento. Este anel é bipartido, podendo ser retirado sem a necessidade de desmontar as outras partes do molde ou da desmoldagem do corpo-de-prova (CP). Com a remoção do anel intermediário, uma faixa de $10 \mathrm{~mm}$ de altura fica livre no corpo-de-prova. Essa faixa livre coincide com a interface, região onde deve ocorrer o cisalhamento. 0 restante do CP permanece confinado para o ensaio. A Figura 3 apresenta o esquema de montagem do molde.

A compactação por impacto, através de soquete Marshall, foi definida por ser comumente empregada em dosagens de concreto asfáltico, além de materiais granulares também serem compactados em laboratório por impacto. 0 formato cilíndrico do molde foi estabelecido 
considerando que a moldagem de corpos-de-prova prismáticos apresentaria maiores dificuldades. 0 diâmetro interno definido, de 101,5 mm, é o mesmo dos moldes Marshall, o que faz que a amostra seja compactada em seção plena, deixando a superfície já pronta com a compactação.
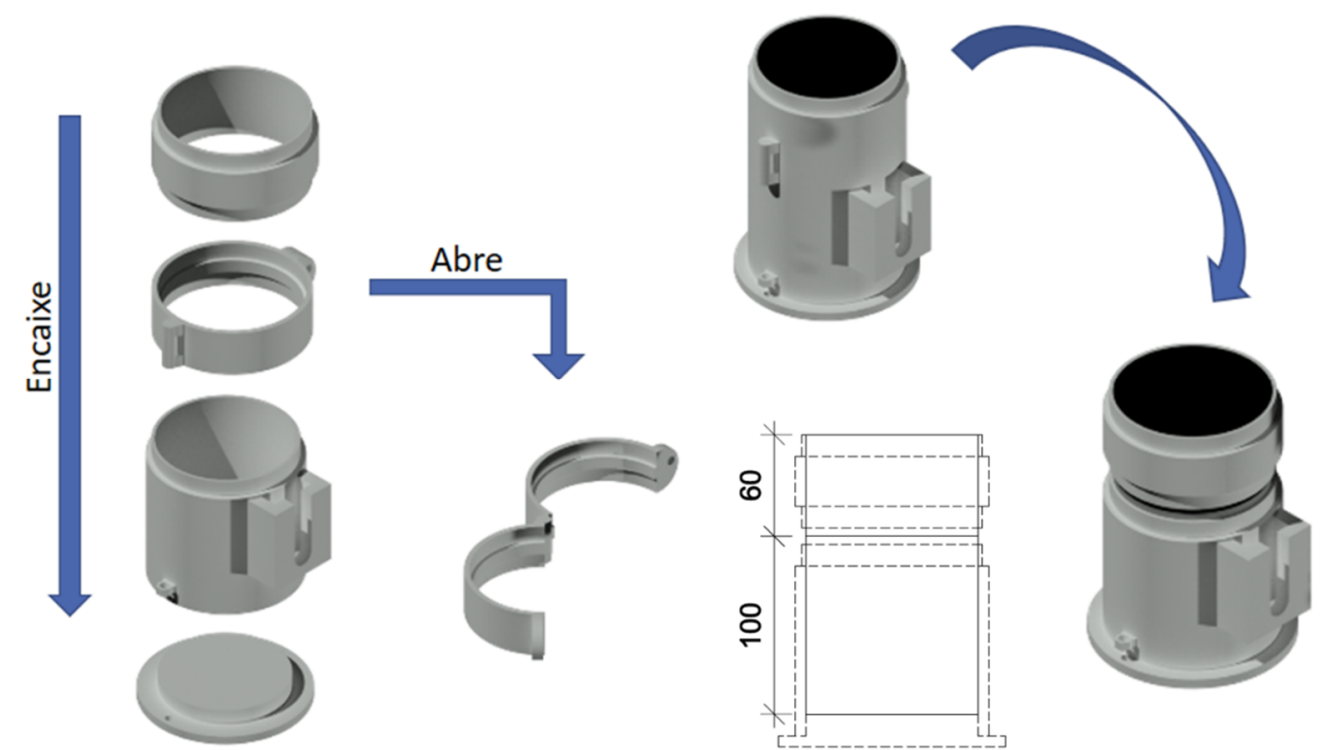

Figura 3. Esquema com elementos e montagem do molde para o ensaio de cisalhamento desenvolvido

A moldagem dos corpos-de-prova é realizada por etapas. Inicia-se com a compactação da camada de base. Após sua cura, realiza-se o tratamento de interface que se deseja avaliar, caso haja, como com a aplicação de asfalto diluído e/ou emulsão asfáltica. Por fim, é moldada a segunda camada, com o material de revestimento. Após a moldagem, realiza-se o condicionamento térmico e o processo de ruptura por cisalhamento.

\subsubsection{Aparato de Ensaio Desenvolvido}

Devido à dupla aplicação de carga, normal e cisalhante, foi desenvolvido um aparato de ensaio que recebe o corpo-de-prova e é montado em uma prensa servo-hidráulica UTM. Com este aparato é possível realizar o ensaio de cisalhamento fazendo com que previamente a amostra receba a tensão normal, na forma de condicionamento, que será mantida durante o cisalhamento. Isso faz com que o processo de ruptura, após o condicionamento térmico, se dê em duas etapas, na primeira ocorre a aplicação da tensão normal e na segunda, mantendo a tensão normal sobre a amostra, é realizado o cisalhamento da interface. Esta divisão se deu por não ser possível a aplicação simultânea da tensão normal e do deslocamento cisalhante com os equipamentos disponíveis.

Para a realização do ensaio, o aparato desenvolvido é montado na prensa e recebe os corposde-prova com o anel intermediário já removido. 0 equipamento possui uma peça móvel, com rolamentos ("carrinho"), que permite o deslocamento da camada inferior do CP com baixo atrito, uma rótula para a adequada aplicação da tensão normal, hastes roscadas e placas, que mantêm a tensão normal durante o cisalhamento e uma placa base, que apoia e fixa o restante do conjunto à prensa. A Figura 4 apresenta o esquema dos componentes do aparato de ensaio.

Todos estes elementos indicados na Figura 4 também foram produzidos em aço. 0 "carrinho" (A) é composto de uma placa com três pinos para o encaixe em posição correta do fundo do molde em sua parte superior e quatro rolamentos em sua parte inferior. A rótula (C) é composta 
de dois discos, com diâmetro igual ao diâmetro interno dos moldes e uma esfera. A placa base (E) é uma placa de aço que serve de base para o restante do aparato, montada sobre a mesa da prensa a fim de aumentar a área de apoio para as demais partes. Além disto, serve para prender o anel superior através das barras roscadas e da haste em (D), e também afixar o conjunto em (B). 0 conjunto em (B) da Figura 4 possui uma placa inferior, quatro hastes com rosca, um apoio em "Y" e uma placa superior. As barras roscadas são fixas na placa inferior, em seus quatro cantos. Além disto, na mesma placa é fixa uma estrutura em "Y" que ajuda na centralização do corpo-de-prova e apoia o molde na etapa de cisalhamento. A placa superior deste conjunto é removível. 0 esquema de montagem é mostrado na Figura 5.
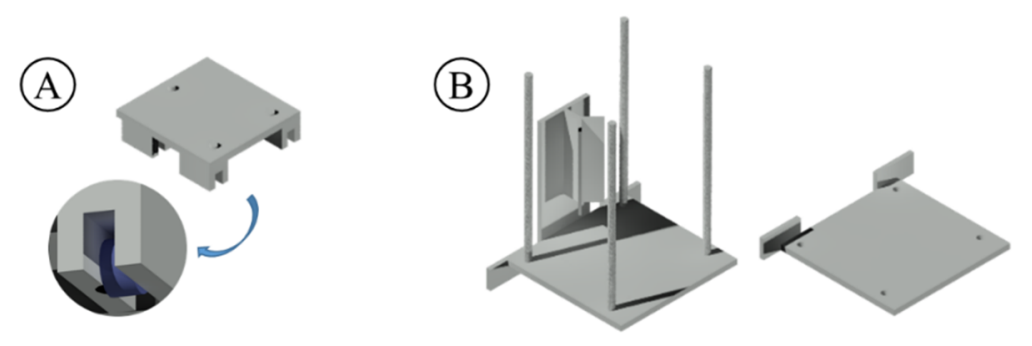

(C)

(D)

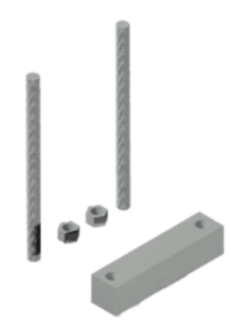

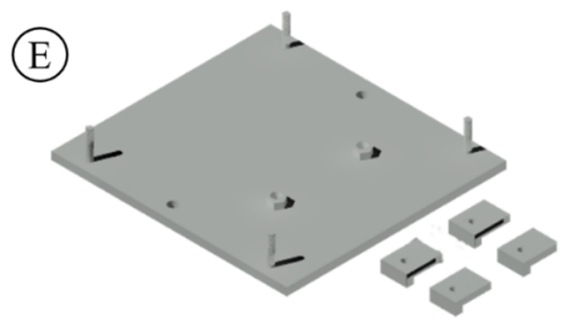

Figura 4. Esquema dos componentes do aparato de ensaio desenvolvido

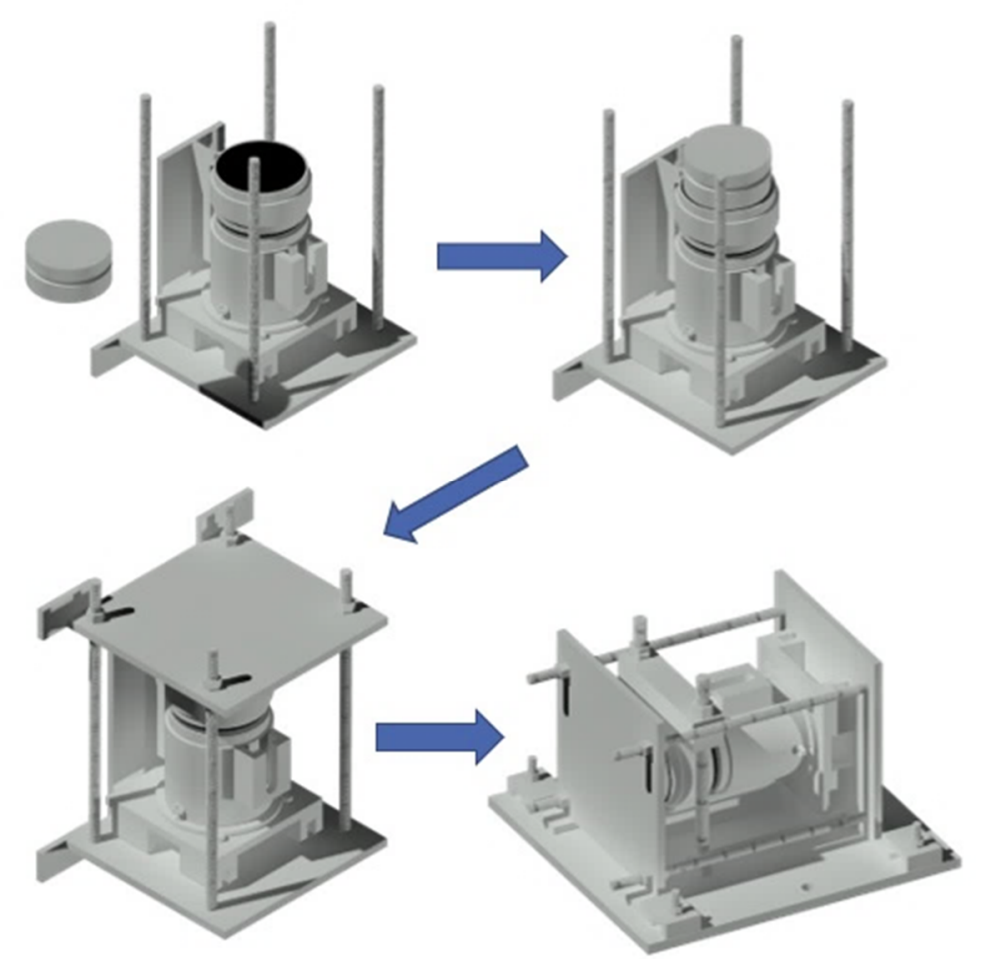

Figura 5. Esquema de montagem para o ensaio desenvolvido 


\subsubsection{Aplicação Prévia da Tensão Normal}

O procedimento de ruptura inicia com a aplicação da tensão normal. Primeiramente é removido o anel intermediário do molde, que deixa livre a interface das camadas. Em seguida, este é posicionado sobre o carrinho (A) e o carrinho sobre a placa inferior do conjunto (B) da Figura 4. 0 molde sobre o carrinho deve encostar no apoio em Y e deve ter o suporte para o atuador da prensa votado para o lado oposto ao apoio. Sobre o revestimento é posicionada a rótula (C) e, sobre esta, a placa superior do conjunto (B), encaixada nas hastes roscadas. Aplica-se então o carregamento com a prensa, apertam-se as porcas e, em seguida, cessa-se a aplicação da carga normal com a prensa. A Figura 6 mostra, de (A) a (C), o procedimento de montagem para aplicação da tensão normal.
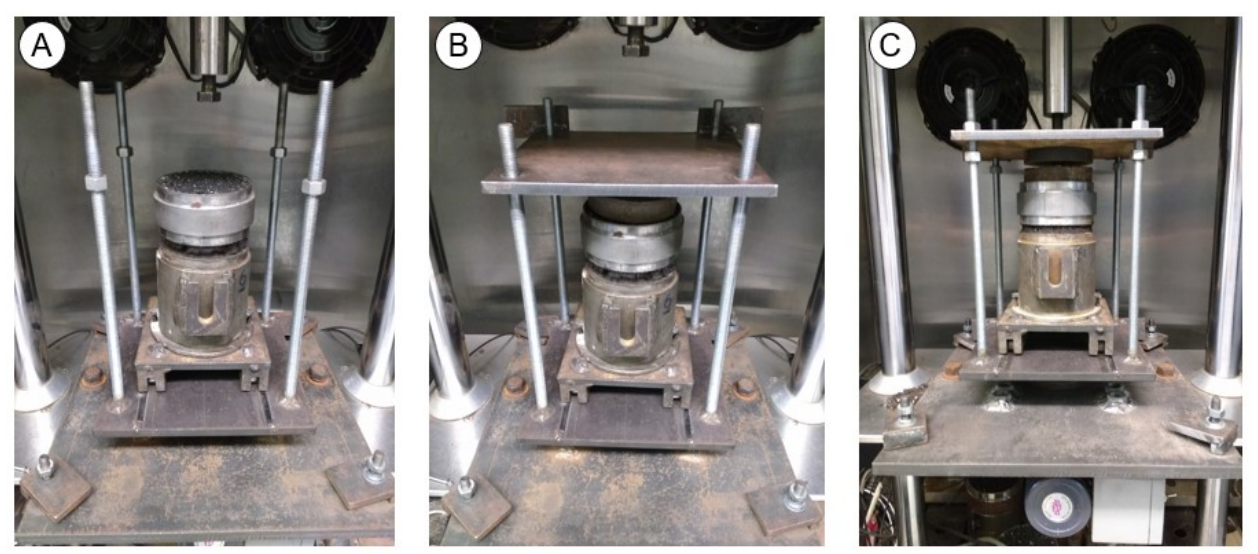

Figura 6. Etapas de montagem do equipamento para aplicação da tensão normal

Devido à esta aplicação ser prévia ao cisalhamento, é necessário garantir que a tensão normal residual, mantida pelo aparato de ensaio desenvolvido sobre o corpo-de-prova na segunda etapa da ruptura (o ensaio de cisalhamento), após cessada a aplicação do esforço normal, seja aquela estipulada. Assim, deve-se realizar uma verificação que permita definir a força necessária a ser aplicada com a prensa e o aperto das porcas sextavadas a ser utilizado para que, cessada a aplicação de carga, a tensão normal residual sobre o corpo-de-prova seja, em média, a estipulada. Para os ensaios de avaliação da metodologia desenvolvida, que serão apresentados em 3.2, este procedimento foi efetuado com uma célula de carga tipo disco, com capacidade para até 5 toneladas.

Para a aplicação da tensão normal, a célula de carga foi posicionada sobre a rótula e esta sobre um corpo-de-prova moldado, visando considerar a deformabilidade dos materiais sob ação do carregamento. Sobre a célula de carga, posicionou-se a placa superior removível do aparato de ensaio e aplicou-se o carregamento com o uso da prensa. Foram realizados sucessivos aumentos de carga aplicada sobre a amostra até ser obtida a tensão escolhida. A padronização do aperto das porcas sextavadas foi realizada com o controle do ângulo de aperto destas com chave-de-boca, após todas estarem encostadas na placa superior sem serem apertadas. Deste processo foi possível obter a média e o desvio-padrão que caracterizam a tensão residual sobre o corpo-de-prova, que é aquela atuante no início do cisalhamento e cujos resultados estão em 3.2. 


\subsubsection{Procedimento para o Ensaio de Cisalhamento}

Para a aplicação do cisalhamento no ensaio desenvolvido, o conjunto (B) da Figura 4 com o CP deve ser deitado sobre a placa base (E) da Figura 4, afixada na mesa da prensa, e então o anel inferior do molde engatado pelo suporte ao atuador da prensa. Após isto, o anel superior é preso à placa base, bem como o conjunto $(\mathrm{B})$ da Figura 4. Inicia-se então a aplicação do deslocamento definido de 50,8 $\mathrm{mm} / \mathrm{min}$. Tal deslocamento é realizado pelo atuador da prensa, que sobe 20 $\mathrm{mm}$, levando consigo o anel inferior do molde e o "carrinho", gerando a ruptura da interface. 0 deslocamento de $50,8 \mathrm{~mm} / \mathrm{min}$ foi definido por ser o mais empregado nos ensaios de cisalhamento de interface, como, entre outros, no ensaio de Leutner (1979), no LPDS (RAAB E PARTL, 2009) e no ensaio de cisalhamento FDOT (TASHMAN et al., 2006), apresentados no item de introdução. As etapas de montagem do equipamento para o cisalhamento são mostradas na Figura 7, de (A) até (C). Na mesma figura, em (D) e (E), é mostrado o equipamento posicionado para o início do ensaio, enquanto em (F), tem-se o corpo-de-prova logo após o cisalhamento.
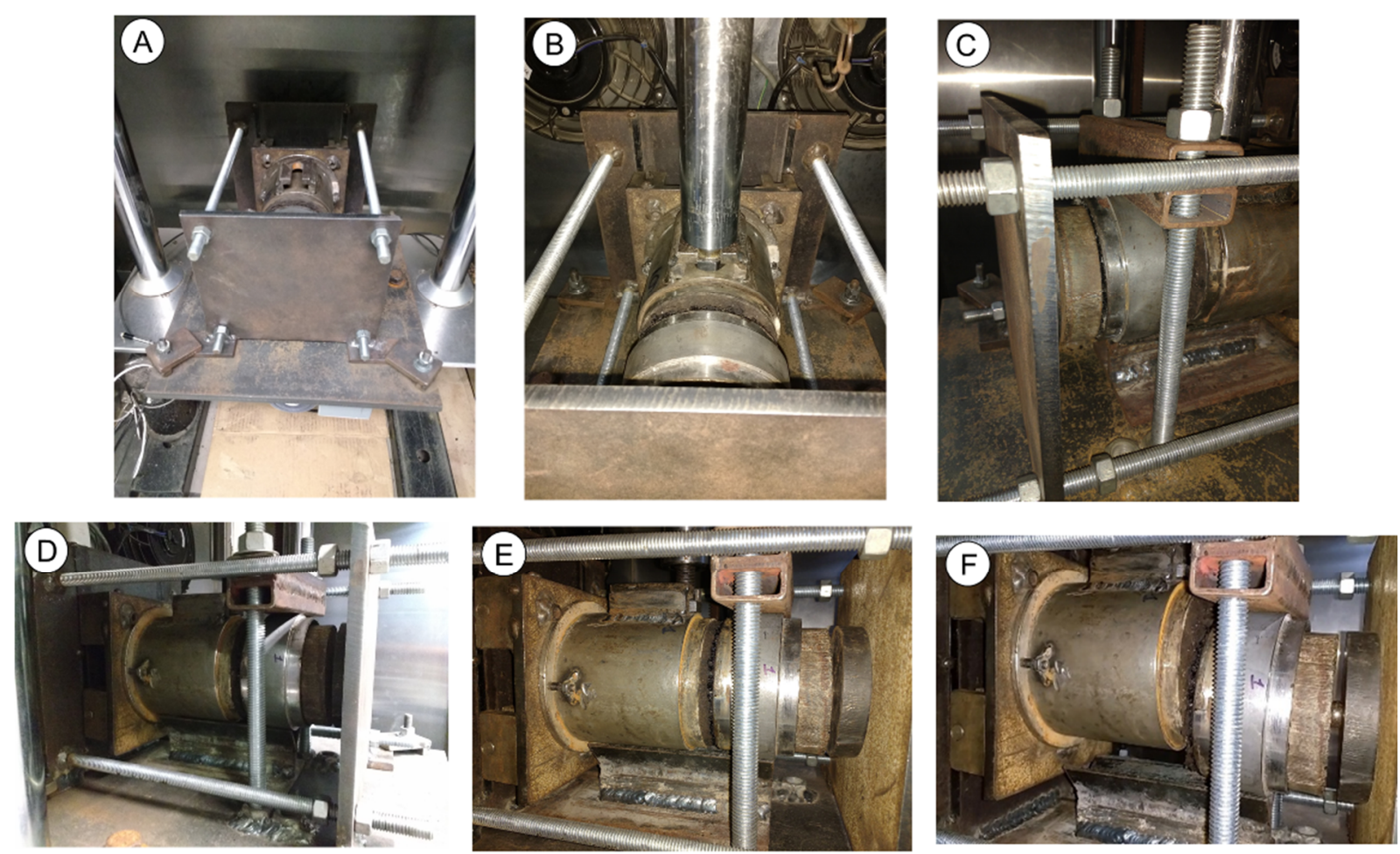

Figura 7. Montagem para a etapa de cisalhamento e ruptura da interface

A utilização da prensa UTM permite um bom controle e a coleta de diversos dados durante o ensaio. Para os ensaios de avaliação da metodologia desenvolvida (3.2), foi empregado o mesmo algoritmo utilizado no ensaio de resistência à tração por compressão diametral. Através dele foram coletados dados de tempo, deslocamento do atuador e de força aplicada a cada 0,01 segundo. Após o ensaio, estes dados foram tabulados e empregados para determinar a resistência ao cisalhamento e o módulo de reação ao cisalhamento.

\subsection{Ensaios para a Avaliação da Metodologia Desenvolvida}

Para comprovar a eficiência do método e do equipamento desenvolvidos, foram realizados ensaios de verificação. Foram empregados três corpos-de-prova para cada tensão normal estipulada (0,55 MPa e 0,83 MPa), compostos de uma camada em BGS e uma em CA, com a interface 
imprimada com asfalto diluído CM-30. Os CPs foram moldados por etapas, a partir da base, onde foi considerada a umidade ótima e a densidade máxima (Figura 8-A), seguindo, após sua curra e limpeza com pincel (Figura 8-B) pela imprimação, em taxa de 0,9 L/m² (Figura 8 -C) e concluindo com o revestimento, moldado considerando a massa específica da mistura (Figura 8-D). Antes da ruptura, as amostras passaram por condicionamento prévio na temperatura definida para os testes $\left(25^{\circ} \mathrm{C}\right)$ (Figura $\left.8-\mathrm{E}\right)$.
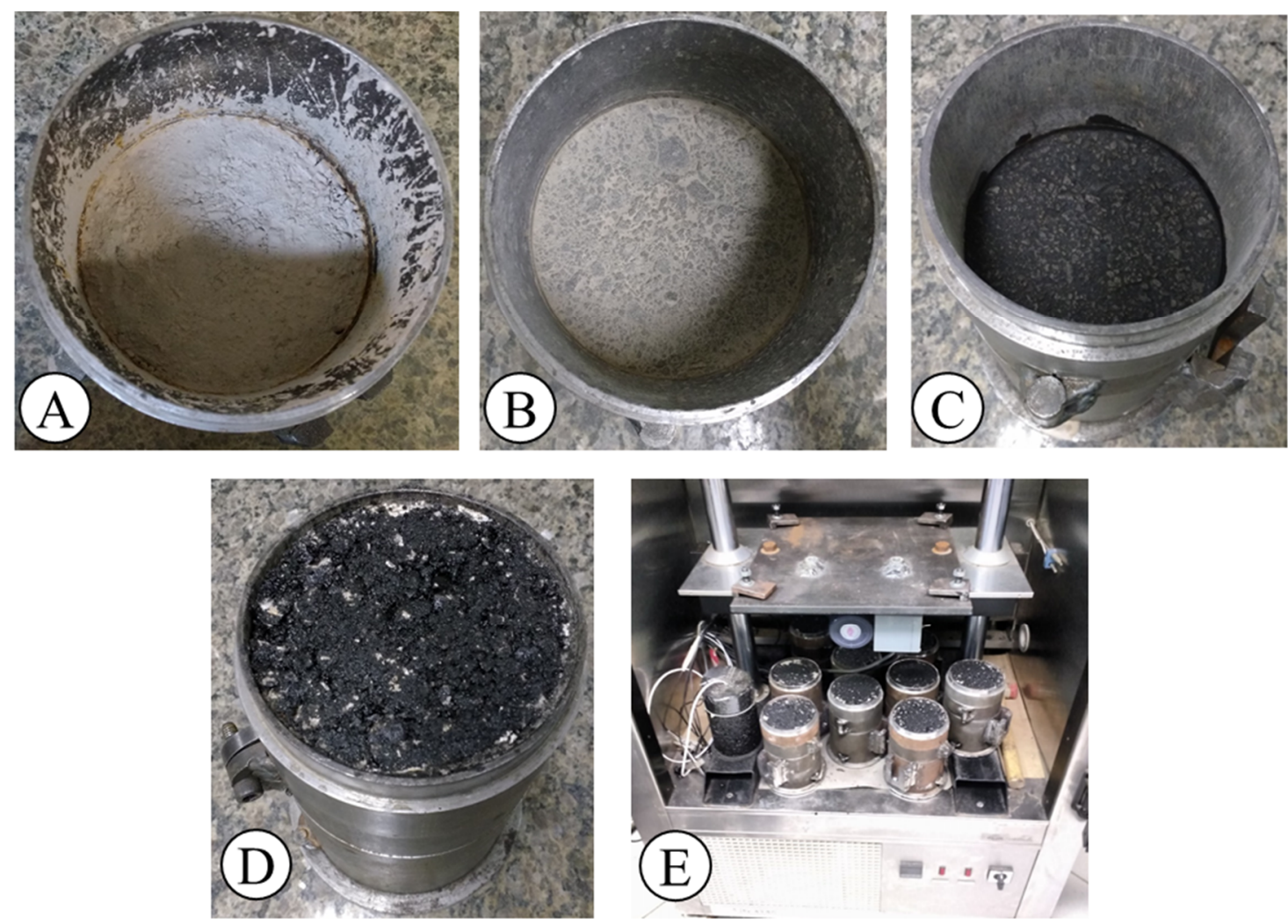

Figura 8. Moldagem das amostras para a avaliação da metodologia desenvolvida

Previamente à ruptura, foi realizada a verificação da carga a ser aplicada com a prensa e do aperto necessário das porcas sextavadas para que sobre a amostra atuasse as tensões normais definidas $(0,55 \mathrm{MPa}$ e 0,83 $\mathrm{MPa})$, o que levou às tensões residuais médias de $0,57 \mathrm{MPa}$ e 0,86 $\mathrm{MPa}$, com desvio-padrão de 0,03 $\mathrm{MPa}$ e 0,02 $\mathrm{MPa}$, respectivamente. Em seguida, os corpos de prova foram rompidos conforme a metodologia desenvolvida, seguindo as etapas apresentadas nos itens 3.1.3 e 3.1.4, e foram coletados, através do software da prensa, dados de tensão de cisalhamento e deslocamento relativo das camadas para cada 0,01 segundo de ensaio.

Os dados coletados automaticamente foram exportados e, em planilha eletrônica, tabulados. Em seguida, foi calculada a área efetivamente cisalhada para cada leitura, que varia no decorrer do ensaio e pode ser obtida geometricamente considerando o diâmetro da amostra e o deslocamento do pistão. Com a área efetivamente cisalhada em cada leitura e a respectiva força de cisalhamento, obtida diretamente do software da prensa, foi determinada a tensão de cisalhamento. Tais resultados são mostrados na Figura 9.

Como pode ser observado, com a utilização do equipamento desenvolvido foi possível avaliar a tensão de cisalhamento na interface ao longo de todo o tempo de ensaio. A resistência ao cisalhamento é obtida do pico das curvas. Nos casos avaliados, para uma mesma tensão normal 
aplicada $(\sigma)$ os resultados foram similares entre si, com uma resistência ao cisalhamento média de 1,12 MPa e desvio padrão de 0,06 MPa para os ensaios com tensão normal de 0,57 MPa e $\tau=1,66 \mathrm{MPa}$, com desvio padrão de 0,12 $\mathrm{MPa}$ para os ensaios com $\sigma=0,86 \mathrm{MPa}$. Por outro lado, para as diferentes tensões normais aplicadas, os valores de resistência ao cisalhamento foram diferentes. Também foi possível a determinação do módulo de reação ao cisalhamento na interface, conforme a Equação (1). Para a tensão normal aplicada de 0,57 MPa, o módulo de reação ao cisalhamento médio obtido foi $0,43 \mathrm{MPa} / \mathrm{mm}$, já para $\sigma=0,86 \mathrm{MPa}$, foi obtido $\mathrm{K}=0,52 \mathrm{MPa} / \mathrm{mm}$.

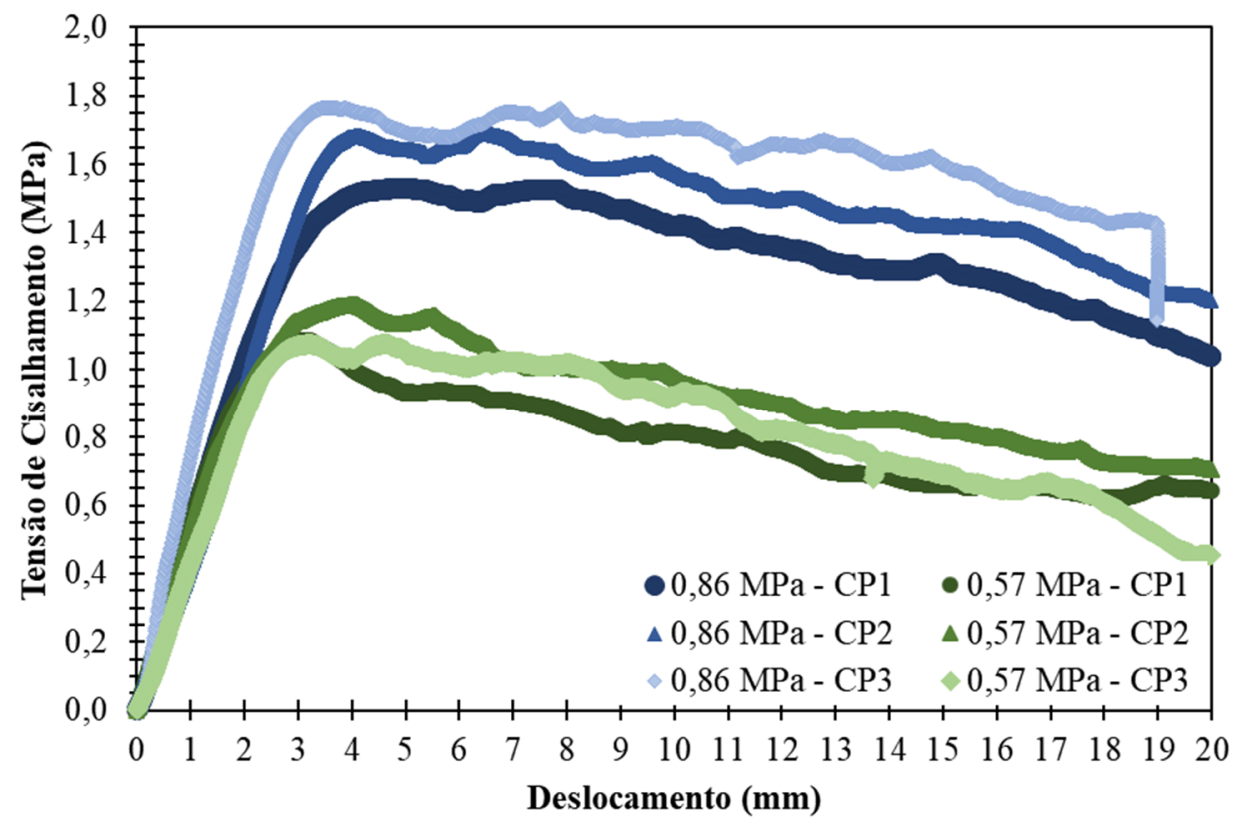

Figura 9. Resultados dos ensaios de verificação do equipamento

Conforme já mencionado, o desenvolvimento desta metodologia de ensaio se deu com vistas a uma futura pesquisa de avaliação da aderência entre camadas de base granular e revestimento asfáltico de pavimentos. Uma forma de avaliar a aderência a partir dos valores obtidos é empregando os resultados de Uzan et al. (1978) e Kruntcheva et al. (2005). Estes autores realizaram avaliações numéricas que relacionam aderência com o valor de $\mathrm{K}$ em interfaces de camadas asfálticas. Seus resultados indicam que se o módulo de reação ao cisalhamento é maior que $100 \mathrm{MPa} / \mathrm{mm}$, a interface está aderida, enquanto se Ké menor que 0,1 MPa/mm, a interface não está aderida.

Os valores hora apresentados, apenas para exemplificar a utilização prática desta metodologia de ensaio, forneceriam resultados mais adequados a uma condição de não aderência na interface. Isto vem ao encontro ao estabelecido no novo método de dimensionamento de pavimentos brasileiro (MeDiNa). Um maior estudo de avaliação da aderência com o uso desta metodologia, contudo, está sendo desenvolvido, considerando diferentes tipos de interfaces, com amostras rompidas sob diferentes tensões normais e, através de condicionamento com diferentes temperaturas de ensaio.

\subsection{Verificação da Influência do Atrito do Equipamento nos Resultados dos Ensaios}

Um fator que poderia influenciar nos resultados obtidos com a metodologia desenvolvida era o 
atrito no equipamento de ensaio. Tal atrito poderia ocorrer nos rolamentos do "carrinho" e no contato deste com a placa inferior do aparato de ensaio, nos locais indicados na Figura 10, nos quatro rolamentos.

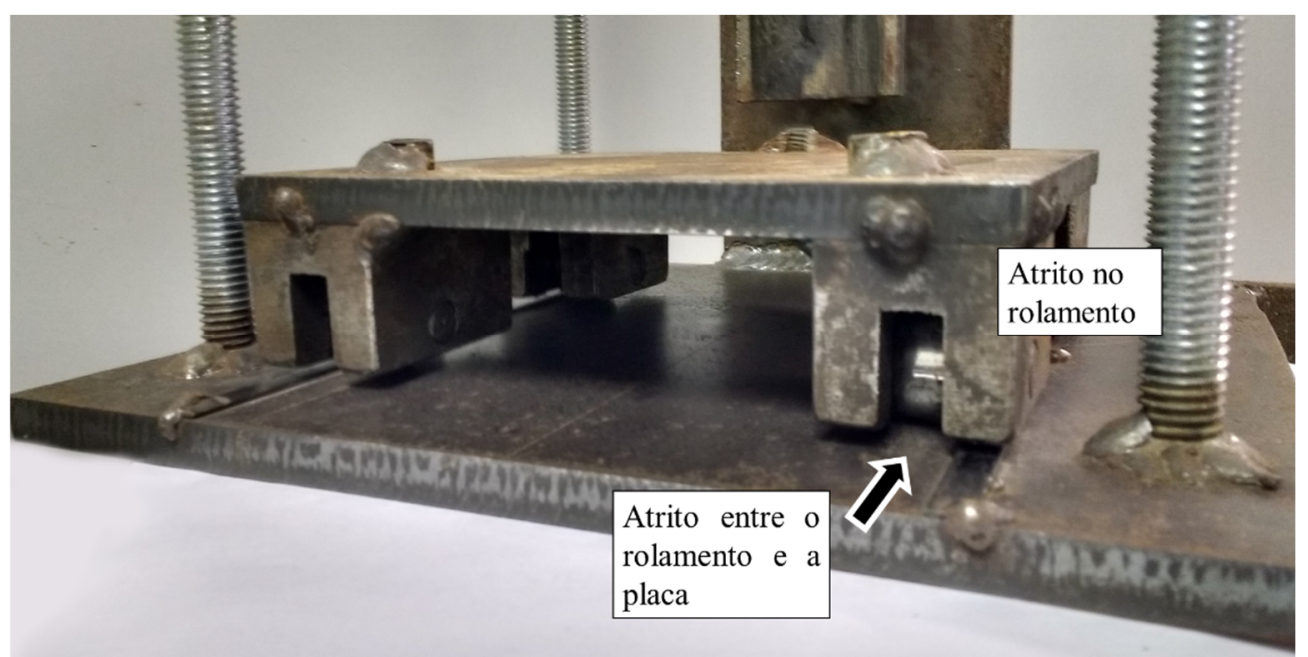

Figura 10. Atrito no equipamento desenvolvido

A fim de determinar se os resultados obtidos através do equipamento desenvolvido sofriam influência significativa do atrito deste, realizou-se uma verificação experimental. Para tal, era necessário o emprego de um corpo-de-prova, porém com resistência de atrito ao cisalhamento da interface desprezível, para ser captada a influência do aparato sobre as tensões de cisalhamento aferidas. Em vista disto, optou-se pelo uso de dois blocos de gelo, um representando a camada de base e o outro a de revestimento, congelados já separadamente, baseando-se no fato das camadas de gelo apresentar baixo atrito entre si.
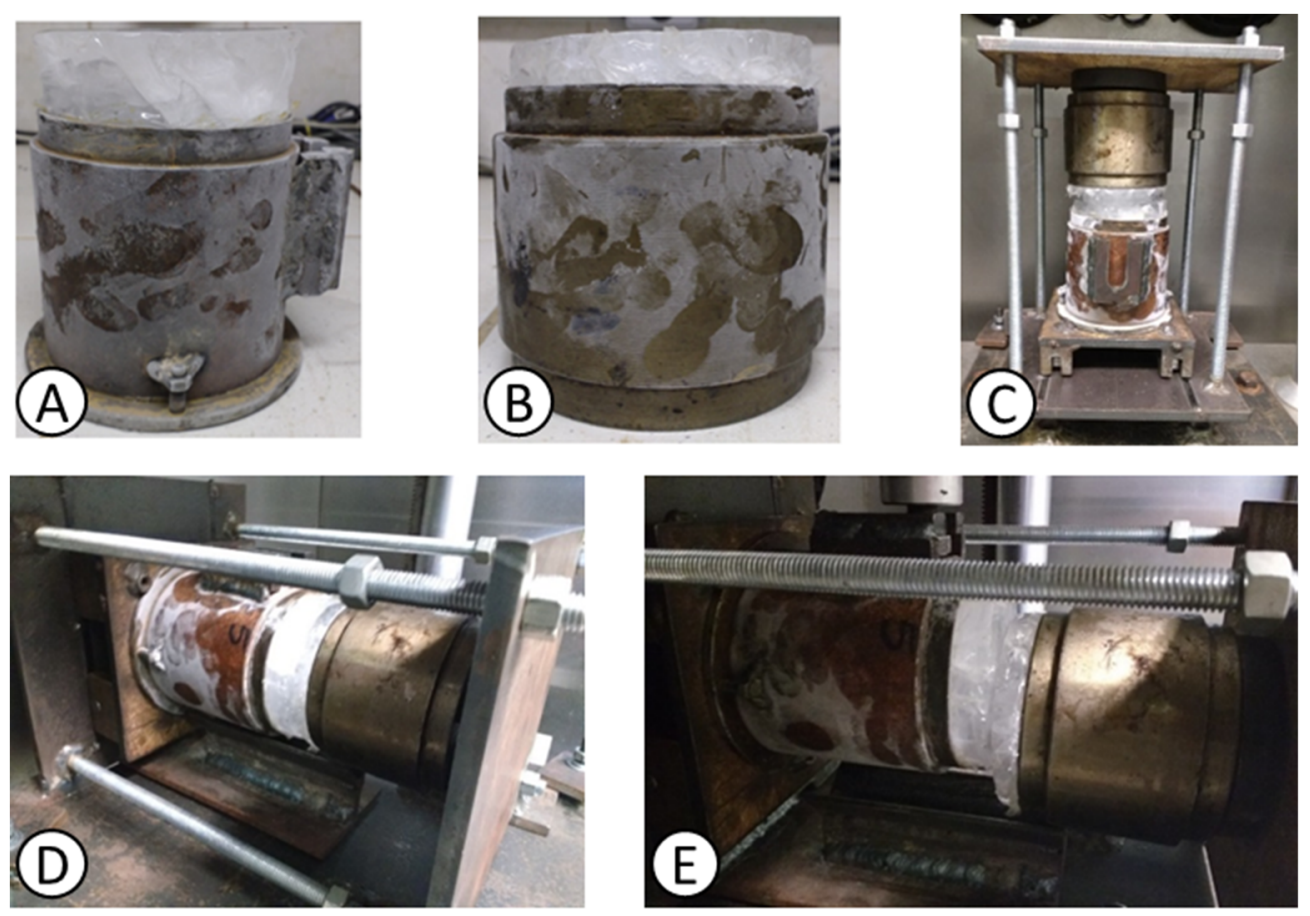

Figura 11. Ensaio para a determinação da influência do atrito do equipamento 
Realizou-se o ensaio de cisalhamento da maneira como apresentado em 3.1.3 e 3.1.4. Neste caso, contudo, já não havia ligação entre as duas partes envolvidas. A Figura 11 mostra em (A) e (B) os blocos empregados, com a face onde ocorre o cisalhamento retificada em chapa aquecedora, para estarem planas e paralelas; em (C), o conjunto montado para a aplicação da tensão normal; em (D), o equipamento posicionado para a fase de cisalhamento e; em (E), o equipamento e o CP após o termino do ensaio.

A Figura 12 apresenta os resultados obtidos. Pode-se perceber em alguns casos um pico na resistência ao cisalhamento no início do ensaio, seguido de uma queda brusca. Tal pico deve-se a cristalização da interface, que fez com que a fina película de água líquida na superfície dos blocos independentes, que surge naturalmente no início do manuseio dos CPs e com a aplicação da tensão normal, congelasse, propiciando a união dos mesmos. Devido a isto, tais picos foram desprezados.

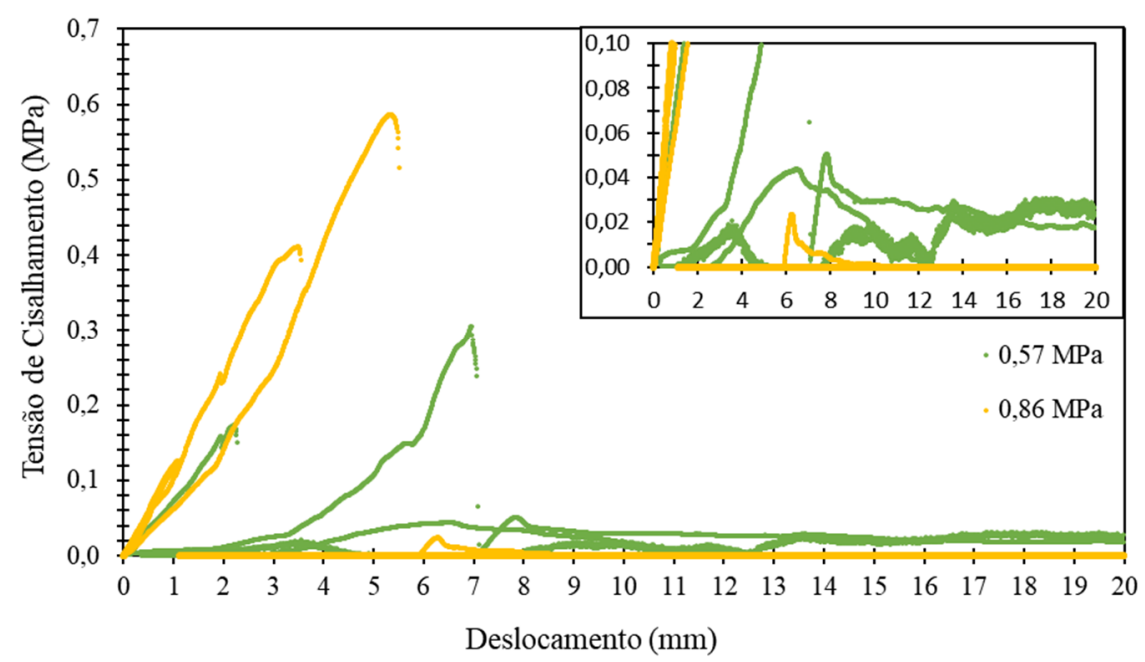

Figura 12. Resultados da determinação do atrito

Assim, considerando os resultados de tensão de cisalhamento obtidos após a ruptura da cristalização da interface e comparando com os valores dos ensaios realizados para a verificação da eficiência do equipamento, pôde-se observar que os resultados de atrito são baixos, em torno de 0,02 MPa, sendo, portanto, considerados desprezíveis. Devido a isto, pode-se considerar que $o$ atrito do equipamento tem pouca interferência nos valores de tensão de cisalhamento mensurados com seu uso, sendo os resultados representativos da real resistência da interface.

\section{CONSIDERAÇÕES FINAIS}

Como demonstrado, foi possível elaborar um ensaio de resistência ao cisalhamento da interface de duas camadas de materiais. Este ensaio se mostrou aplicável para a avaliação da resistência de interface ao cisalhamento quando uma das camadas é de material não aglutinado, pois foi possível garantir seu confinamento da moldagem até a ruptura. Também foi possível a realização do cisalhamento com a atuação de tensão normal controlada sobre a amostra, utilizando um aparato de ensaio desenvolvido na pesquisa. Além disto, a montagem na prensa UTM propiciou a coletada de dados para a determinação da tensão de cisalhamento e do deslocamento relativo das camadas a cada 0,01 segundo, permitindo ainda a determinação do módulo de reação ao cisalhamento. 
Os ensaios de verificação realizados comprovaram a eficiência do equipamento e do método desenvolvidos. Comparando os resultados dos ensaios de verificação com os da determinação do atrito, percebeu-se que a influência do equipamento é pouco significativa, sendo que os valores de resistência ao cisalhamento obtidos com o uso do equipamento representam a real resistência da interface. Assim, a metodologia apresentada é aplicável à avaliação do cisalhamento em interfaces, podendo ser empregado em pesquisas voltadas à determinação da aderência entre camadas de pavimentos. Além disto, o equipamento desenvolvido mostra potencial para utilização também em outras avaliações de cisalhamento, inclusive sob temperaturas diferentes.

\section{AGRADECIMENTOS}

À CAPES pela bolsa de mestrado do primeiro autor e à REDE EM TECNOLOGIA DE ASFALTO ANP/PETROBRAS pelo apoio às pesquisas do GEPPASV/UFSM.

\section{REFERÊNCIAS}

Canestrari, F.; G. Ferrotti; M. N. Partl.; E. Santagata (2005) Advanced Testing and Characterization of Interlayer Shear Resistance. Transportation Research Record: Journal of the Transportation Research Board, n. 1929, Transportation Research Board of the National Academies, Washington, D.C., p. 69-78. DOI https://doi.org/10.3141/1929-09

Canestrari, F.; G. Ferrotti; L. Xiaohu; A. Millien; M. N. Partl; C. Petit; A. Phelipot-Mardelé; H. Piber e C. Raab (2013) Mechanical Testing of Interlayer Bonding in Asphalt Pavements. In Partl, M. N.; U. B. Hussain; F. Canestrari.; C. De La Rroche; H. Di Benedetto; H. Piber e D. Sybilski. Advances in Interlaboratory Testing and Evaluation of Bituminous Materials, Cap. 6, RILEM, 2013. DOI 10.1007/978-94-007-5104-0_6

Guimarães, P. A. (2013) Estudo da Aderência Entre Camadas Asfálticas de Pavimentos. 189 p. Dissertação (Mestrado em Engenharia Civil) - Escola Politécnica da Universidade de São Paulo, Universidade de São Paulo, São Paulo.

Kruntcheva, M. R.; A. C. Collop; N. H. Thom (2005) Effect of Bond Condition on Flexible Pavement Performance. Journal of Transportation Engineering, ASCE, v. 131, n. 11. DOI http://dx.doi.org/10.1061/(ASCE)0733-947X(2005)131:11(880)

Leutner, R. Untersuchung des Schichtverbundes beim bituminösen Oberbau. Bitumen 3, Hamburg, 1979.

Miró R., R.; A. Martínez, J. F. Pérez. (2006) Evaluation of effect of heat-adhesive emulsions for tack coats with shear test: From the road research laboratory of Barcelona. Transportation Research Record: Journal of the Transportation Research Board, n. 1970, p. 64-70. DOI https://doi.org/10.3141/1970-08

Raab, C.; M. N. Partl (2009) Interlayer bonding of binder, base and subbase layers of asphalt pavements: long-term performance. Construction and Building Materials. 23(8), 2926-2931. DOI https://doi.org/10.1016/j.conbuildmat.2009.02.025

Raposeiras, A. C.; D. Castro-Fresno; A. Vega-Zamanillo; J. Rodriguéz-Hernandez. (2013) Test methods and influential factors for analysis of bonding between bituminous pavement layers. Construction and Building Materials, v. 43, Jun, p. 372-381. DOI https://doi.org/10.1016/j.conbuildmat.2013.02.011

Santos, A. G.; R. K. M. Assis; J. L. Fernandes Jr. (2017) Influência da Condição de Interface das Camadas na Previsão de Desempenho de Pavimentos Flexíveis. Anais XXXI ANPET, XXX Congresso Nacional de Pesquisa em Transportes ANPET, Recife, 2017.

Scherer, R. G., L. D. Bueno, D. S. Pereira, L. P. Specht, G. S. Trindade (2016) Influência da Aderência entre Camadas no Desempenho Esperado de Pavimentos Asfálticos. Anais XXX ANPET, XXX Congresso Nacional de Pesquisa em Transportes ANPET. Rio de Janeiro, RJ.

Sutanto, M. H. (2009) Assessment of Bond Between Asphalt Layers. 293 p. Tese (Doctorate in Philosophy) - Nottingham Transportation Engineering Center, University of Nottingham, Nottingham.

Tashman, L.; K. Nam; T. Papagiannakis (2006) Evaluation of the Influence of Tack Coat Construction Factors on the Bond Strength Between Pavement Layers. Report of Washington Center for Asphalt Technology, WCAT, Final Report \#06-002, Pullman, WA.

Torquato e Silva, S. A. (2017) Modelagem Mecanístico-Empírica da Interface Revestimento Asfáltico-Base Granular. 101 p. Dissertação (Mestrado em Engenharia de Transportes) - Programa de Pós-Graduação em Engenharia de Transportes, Universidade Federal do Ceará, Fortaleza, CE.

Torquato e Silva, S. A. T., J. B. S. Bastos, J. B. Soares (2015) Influência da Aderência na Análise de Pavimentos Asfálticos. 44º Reunião Anual de Pavimentação. Foz do Iguaçu, PR.

Torquato e Silva, S. A.; R. G. Scherer; J. B. Soares; D. S. Pereira; L. P. Specht (2020) A Thermal Nonlinear Approach for Mechanistic Empirical Modeling of Asphalt-Granular Base Layers Interface" Journal of Testing and Evaluation 48, n. 1 (January/February 2020): 223-234. DOI: https://doi.org/10.1520/JTE20180931

Torquato e Silva, S. A.; J. B. Soares; S. H. A. Barroso (2018) Modelagem Constitutiva e Caracterização Empírica da Interface Revestimento Asfáltico-Base Granular. Transportes, v. 26, n. 2, p. 180-190. DOI 10.14295/transportes.v26i2.1661

Uzan, J.; M. Livneh; Y. Eshed (1978) Investigation of Adhesion Properties Between Asphaltic Concrete Layers. Proceedings of Asphalt Paving Technology, v. 47, p. 495-521. 